\title{
Conservative management of an intrapericardial contained rupture of the right pulmonary artery in blunt trauma: A good idea?
}

\author{
Pierre Demondion, MD, ${ }^{\mathrm{a}}$ Patrick Bellemare, $\mathrm{MD},{ }^{\mathrm{b}}$ and Ismail El-Hamamsy, $\mathrm{PhD}^{\mathrm{a}}$
}

\footnotetext{
From the ${ }^{\mathrm{a} D i v i s i o n}$ of Cardiac Surgery, and ${ }^{\mathrm{b}}$ Intensive Care Unit, Sacre-Coeur Hospital of Montreal, Montreal, Canada.

Disclosures: Authors have nothing to disclose with regard to commercial support.

Received for publication April 4, 2016; revisions received May 5, 2016; accepted for publication June 19, 2016; available ahead of print Aug 25, 2016.

Address for reprints: Ismail El-Hamamsy, PhD, Division of Cardiac Surgery, Sacre-Coeur Hospital, Montreal, Montreal University, Québec, Canada (E-mail: i.elhamamsy@icm-mhi.org).

J Thorac Cardiovasc Surg 2016;152:1435-6

$0022-5223 / \$ 36.00$

Copyright (C) 2016 by The American Association for Thoracic Surgery

http://dx.doi.org/10.1016/j.jtcvs.2016.06.036
}

A 27-year-old man was admitted to the trauma center of Sacre-Coeur Hospital of Montreal immediately after being in a high-velocity snowmobile accident. Clinical examination showed a hemodynamically stable patient with a Glasgow score of 8 , necessitating mechanical ventilation. Computed chest tomography revealed a contained rupture of the intrapericardial right pulmonary artery without pericardial effusion (Figures 1 and 2) accompanied by concomitant right main bronchus laceration and a complete atelectasis of the right lower lung field (Figure 3). Unfortunately, the cerebral scan revealed traumatic brain injury with many intracerebral hemorrhages. Because of the physiologically low pressure in the pulmonary artery and an estimated high risk of cerebral bleeding in the event of heparinization for cardiopulmonary bypass, we decided to offer a

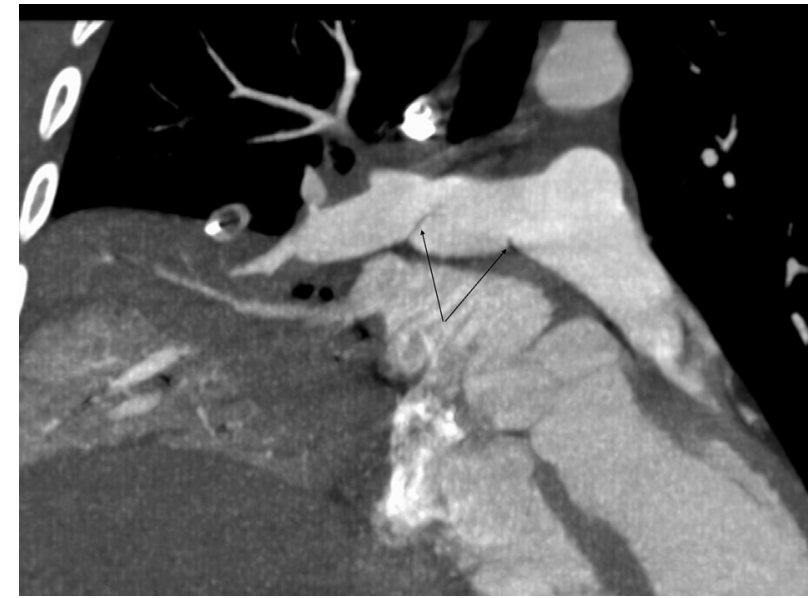

FIGURE 1. Computed tomography scan showing a pseudoaneurysm of the right pulmonary artery (arrows).
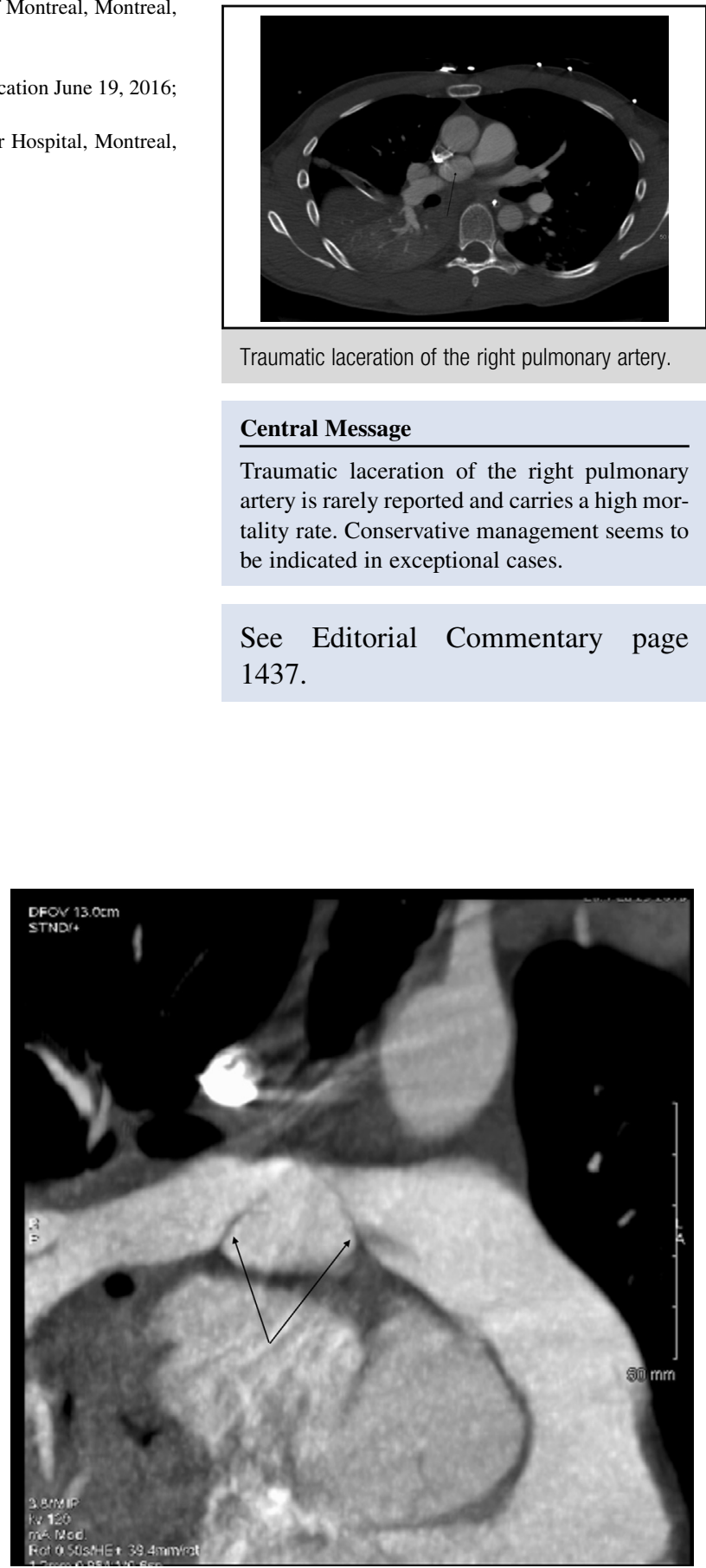

FIGURE 2. Computed tomography scan showing a pseudoaneurysm of the right pulmonary artery (arrows). 


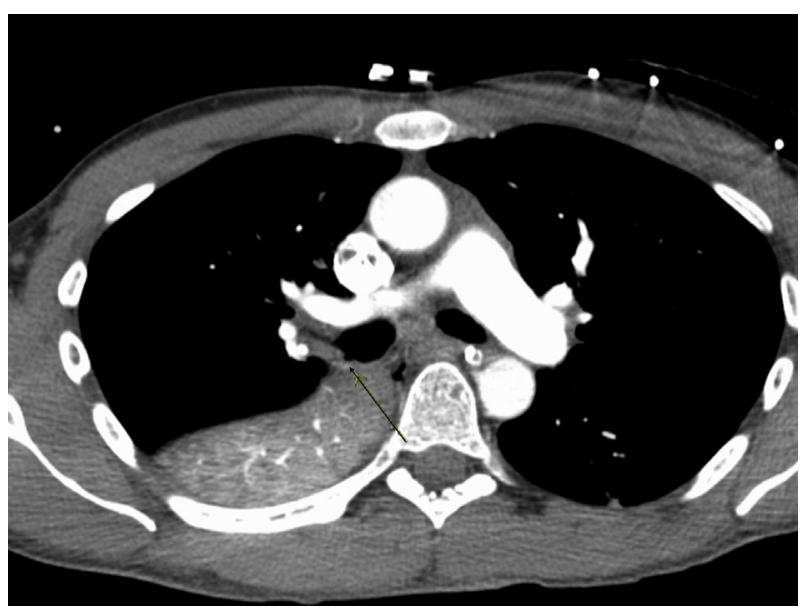

FIGURE 3. Right main bronchus laceration (arrow).

conservative and nonoperative management despite the risk of the pulmonary artery rupture. Unlike patients with a traumatic aortic isthmus injury for which the covered stent graft remains the best treatment even in the case of a head injury, we chose not to offer a covered stent because of our perception of a high risk of pulmonary artery rupture during such a procedure. A pulmonologist made a bronchoscopy and removed a blood clot from the right bronchus that was responsible for lung collapse. The patient remained hemodynamically stable and was extubated at day 5 without significant neurologic sequelae. The control computed tomography scans showed resolution of lung collapse. The right main bronchial injury was asymptomatic and healed quickly. Three months after the accident, the pseudoaneurysm had not increased in size. Considering that there was no longer a risk of intracerebral bleed, surgical repair could have been considered. However, the decision was made to maintain a conservative management. Indeed, we considered that the risk of rupture became negligible because the size of the pseudoaneurysm remained unchanged for 3 months. In addition, the physiologically low pressure in the pulmonary artery was an argument in favor of pseudoaneurysm size stability. We decided to empirically monitor with computed tomography scans every 6 months during the first 2 years. This is an unusual case report describing the successful conservative management of a blunt intrapericardial contained rupture of the pulmonary artery. Indeed, acute pulmonary artery transection after blunt trauma is presumed to be a fatal injury, and surgical repair through an emergency midline sternotomy using cardiopulmonary bypass is mostly recommended. ${ }^{1-4}$ However, in case of heparinization contraindication, an initial conservative management must be considered.

\section{References}

1. Pereira SJ, Narrod JA. Repair of right pulmonary artery transection after blunt trauma. Ann Thorac Surg. 2009;87:939-40.

2. Collins MP, Robinson GC. Traumatic rupture of the pulmonary artery. Ann Thorac Surg. 1989;47:612-3.

3. Clements RH, Wagmeister LS, Carraway RP. Blunt intrapericardial rupture of the pulmonary artery in a surviving patient. Ann Thorac Surg. 1997;64: 258-60.

4. Maury JM, Deslandes L, Oheix S, David JS. Acute traumatic right pulmonary artery rupture in blunt trauma. Intensive Care Med. 2015;41:134-5. 